American Journal of Economics and Business Administration 3 (2): 358-362, 2011

ISSN 1945-5488

(C) 2010 Science Publications

\title{
Capturing Tacit Knowledge for Assessing Employees' Competency and Productivity
}

\author{
${ }^{1}$ Marzanah A. Jabar, ${ }^{2}$ Fatimah Sidi, ${ }^{1}$ Mohd Hasan Selamat, \\ ${ }^{1}$ Abdul Azim Abdul Ghani, ${ }^{2}$ Hamidah Ibrahim and ${ }^{1}$ Salmi Baharom \\ ${ }^{1}$ Department of Information System, \\ ${ }^{2}$ Department of Computer Science, \\ Faculty of Computer Science and Information Technology, \\ University Putra Malaysia, 43400 UPM Serdang, Selangor, Malaysia
}

\begin{abstract}
Problem statement: Organization has to evaluate the competencies of their workers to improve organizational productivity. However, this is difficult because organizations have difficulties to capture and retain knowledge especially tacit knowledge of their employees. Approach: The study reviewed selected literature on management knowledge and employers competencies. It also reviewed existing frameworks in knowledge management focusing on the capturing and storing tacit knowledge. Results: Results of this study will include theoretical concept for capturing tacit knowledge and storing them besides developing a model for measuring employee's competencies in the organization. Conclusion/Recommendation: This study contributes in assessing knowledge workers performance to improve their productivity in an organization.
\end{abstract}

Key words: Tacit knowledge, employees' competency, knowledge management, knowledge process, explicit knowledge, conceptual framework, product approach

\section{INTRODUCTION}

Knowledge in organizations can be categorized into two categories: Explicit or tacit. Explicit knowledge is easily captured and managed. Tacit knowledge is highly personal, available within the individual and difficult to capture and manage. Tacit knowledge when captured is important as it formed the knowledge capital of the organization. Knowledge Management (KM) has generated research interest especially in managing tacit knowledge and is greatly influence by Nonaka knowledge creation theory in (Cheng, 2010; Hafidh et al., 2009; Al-Anzi et al., 2005) Thus, the application of KM has emerged as an approach which enable the capture, storing, reuse and retrieval of knowledge (Adeosun et al., 2009), in improving organization's productivity. Many researchers have acknowledged the limitations of current approaches and techniques to managing tacit knowledge (Asprey, 2004; Sor, 2004). There are not only difficult to conceptualize but much of it is never 'produced', which might cause an organization missing the competitive advantage (Jabar et al., 2009; Sidi et al., 2009). There is an increasing concern in evaluating employees' productivity based on the competencies from tacit knowledge that is acquired through experience and know how as mentioned in (Anand et al., 2010; Elforgani and Rahmat, 2010), for by capturing tacit knowledge, this will influenced the success of an organization.

Knowledge management in an organization: Utilizing knowledge accumulated and generated in an organization is a strategic way to acquire the competitiveness edge for an organization, as discussed by Adeosun et al. (2009); Jabar et al. (2010); Kuppusamy et al. (2008) and Muna et al. (2007)

Tacit knowledge: Following on the work of Jabar et al. (2010), we believe that knowledge starts with a tacit process which comes from individual. Explicit knowledge, unlike tacit knowledge, is defined as knowledge that can be codified and therefore more easily communicated shared and stored in information technology. Among the reasons of difficulties cited in the literature in managing tacit knowledge are due to the reason of tacit knowledge that is inherently elusive, people may not be aware of their tacit knowledge, or people do not want to make it explicit which may result in giving up their valuable competitive advantage Douflou et al. (2004) and Jabar et al. (2010) had proposed the need to convert tacit knowledge into

Corresponding Author: Marzanah A. Jabar, Department of Information System, Faculty of Computer Science and Information Technology, University Putra Malaysia, 43400 UPM Serdang, Selangor, Malaysia 
explicit codified knowledge for sharing and to internalised explicit knowledge. Having the view that tacit knowledge can be transformed into explicit knowledge, information is considered as explicit knowledge of the various types of information and knowledge created, used and transferred in organization Stevens et al. (2010).

\section{MATERIALS AND METHODS}

Knowledge management and competencies assessment framework: Douflo et al. (2004); NyameAsiamah (2009) and Al-Zhrani (2010) suggested that knowledge in an organisation can be used to determine what knowledge can be capitalized. Therefore, explicit knowledge can be handle through knowledge management using $\mathrm{KM}$ tools such as document management, while the tacit knowledge require some formalization. Building on this argument we follow the definition of knowledge as the competence of people and it can be valued and measured internally and externally. Hence competence management in this study is derived from the need to develop a method of formalizing these know-hows for assessing individual productivity. Mark et al. (2006) in managing competencies, put forward that tacit to explicit knowledge took place as user profiles are created and competencies of the people in the organization can be measured based on user profiles as profiling features are usually associated with competence management as in Douflou et al. (2004). User profile can be used to represent a 'snapshot' view of the competencies as a measurement purposes. Information technology has revolutionarised the importance of managing knowledge in an organization. Information processing is seen as an approach in managing knowledge and tacit knowledge can be transformed into explicit knowledge, collected and stored in database. Elmetwaly (2011) and Rao et al. (2008) introduced a paradigm of knowledge used and produced by identifying and localizing knowledge; formalizing it; distributing it and maintaining it.

Based on the literature review on the framework put forward earlier, it can be said that the approach of knowledge management are inclined towards people and process centric, which in the knowledge management processes covering the capture, preservation, sharing and reuse of knowledge as stated in Jabar et al. (2009). In a people centric approach, it starts with the primary intangible resource that is the competence of people, to create value to the organization. Works by Lindgren et al. (2003), tend to emphasized more on the technology and product centric approach, as new knowledge is created in the knowledge creation process; it needs to be stored for later use. These processes take place during the knowledge development until the knowledge maintenance process as described by Nyame-Asiamah, (2009) and Al-Zhrani (2010). With the use of technology, organization developed repositories of organization knowledge, so that it can be retrieve or transfer at any time. Based on these work, it can be said that people and process centric as well as technology product approaches are two main perspectives normally adopted in many KM research as well as KM application (Vandaie, 2008). The technology and product approach implies that knowledge are objects that can be located and manipulated and is possible to capture, distribute measure and manage (Jabar et al., 2010). Since knowledge and competencies are closely related however not much attention is being given in managing competencies as noted in the study of Lindgren et al. (2003). Further studies have noted competencies as an abstraction of task and a measurement for measuring human abilities and competencies. We feel that study must be made to capture tacit knowledge, when employees leave or become unavailable. This is further encouraged, to help us understood and accurately reflect the employee's productivity. This is supported with the need to manage employee's competencies for competitiveness edge in an organization.

\section{RESULTS AND DISCUSSION}

Conceptual framework: KM framework discussed earlier has discusses on the view that focuses on people and process. Technology and product approach focuses on how to store and make knowledge accessible to people. We argue that since people are the source of tacit knowledge hence the knowledge of people, it is proposed that tacit knowledge is conceptualized and formalized through knowledge process and a model for competencies can be identified as shown in Fig. 1. In formalizing it, a structure of knowledge for the organization is built as an inventory of knowledge product.

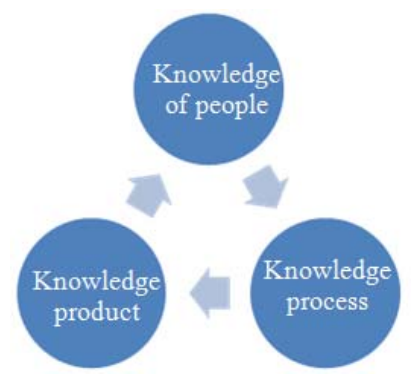

Fig. 1: 3P of knowledge (People, Process and Product) 


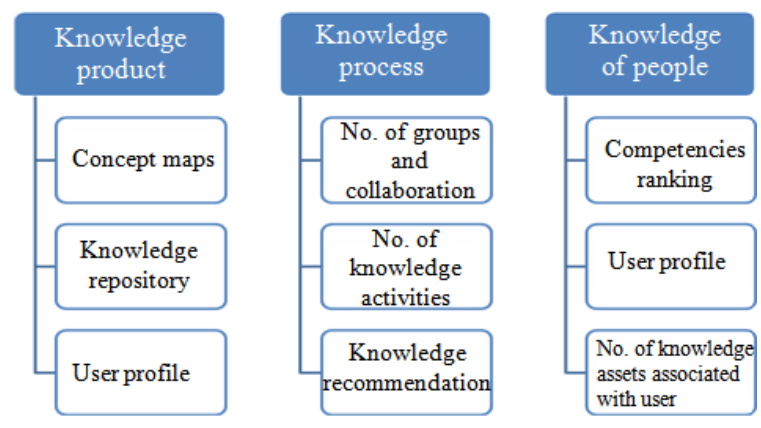

Fig. 2: Elements of 3P of Knowledge (People, Process and Product)

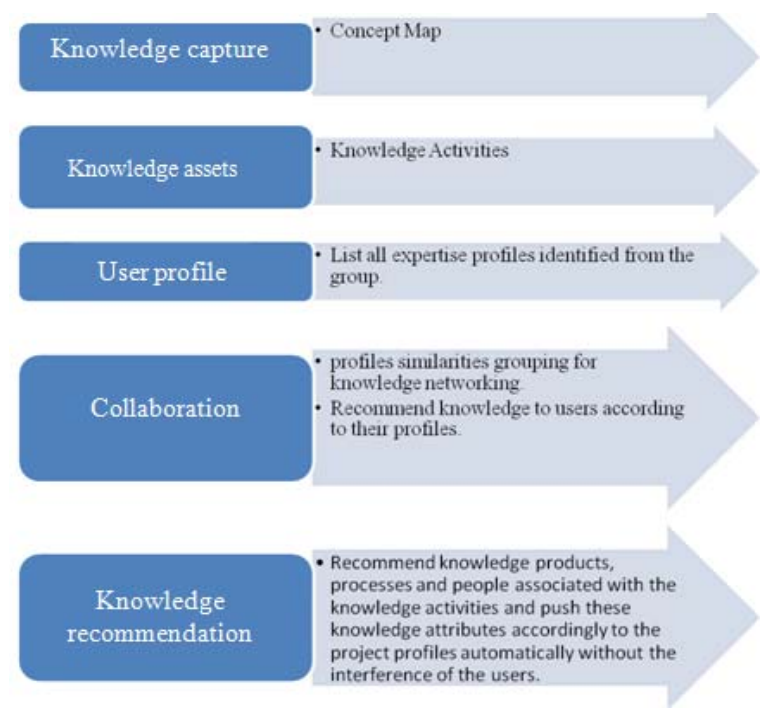

Fig. 3: Measurable Items of 3P of Knowledge

In this proposed conceptual knowledge framework, the knowledge process will describe an event where the know-how of a person is externalized. Knowledge product is the output of externalizing the know-how that can be located and manipulated as an object, which is possible to capture, distribute and manage. Knowledge of people refers to the knowledge of competencies and profiles of its employees in an organization. Elements based on the 3P of knowledge as the basis for competencies evaluation in an organization are also identified as in Fig. 2.

Knowledge product: Knowledge product is referred to as an object that can be identified and handled in information systems. Knowledge product proposes comprises of the tacit knowledge captured into the concept map database, by applying concept mapping for knowledge capture technique, tacit knowledge are captured in a free and informal way (Novak and Canas 2006; Hanekamp (2008)). To have an effective mechanism in managing knowledge, knowledge structures based on some classification schemes are stored in a repository and represented as: Knowledge Asset, Knowledge Activities, User Profile and Knowledge Domain. User profile generations are use for the purpose of personalization and categorization of employees. In this study, we proposed a method of user profile creation and identified as user competency profile. The competency profile will represent the knowledge and competencies associated with a user. Similarity measures algorithm (Merali and Davies, 2001; Marshall and Madhusudan, 2004) will be used in deriving the competencies scale of each user. By having competencies scale, it provides an overview of employees' competencies in organization which is valuable for the management in assessing their productivity.

Knowledge process: In knowledge process, human interactions in knowledge creation are identified based on personalization process where knowledge relevant to the users were pushed as knowledge seeking activities, based on recommendations from the user profile. Discovering and understanding user profile patterns provided personalized knowledge recommendation services based on similarity measure of user profiles. Profiling and personalization technique are used to identify experts, potential areas for collaboration and knowledge networks.

Knowledge of people: Knowledge about expertise profiles or competencies profiles are identified based on the knowledge contribution structured in the knowledge product. The scale of 0 to 1 denotes the level of similarities to the knowledge domain, the higher the number dictates the similar knowledge of the expertise to the knowledge domain. The ranking are used to form some understanding on the competencies of an expert based on their knowledge.

Structural model for competencies: The possible outcome identified from the elements of 3P knowledge (Fig. 2), are identified as the measurable items in Fig. 3 and on further analysis of possible outcomes, we proposed the indication of competencies as mapped to the value creating capabilities in measuring knowledge in an organization.

The metrics is proposed to be utilized in managing tacit knowledge and competencies evaluation purposes Basu and Datta (2010). The outcome metrics in will provide a method to express an organization vision and 
strategy on tangible terms for the project, with primary focus on the productivity of its people and tacit knowledge. To validate the result we propose, a pre and post questionnaires on the measurable items from the 3P elements (Jabar et al., 2009). The questionnaires will be conducted to verify on the competencies management in the organization.

\section{CONCLUSION}

The conceptual framework discussed on the theoretical background that builds on the view of knowledge as the strategic resource of the organization. The framework would provide an innovative approach for leveraging knowledge that built around the 'product', 'process' and 'people' approach in the knowledge management perspective. The framework represents the knowledge strategy, processes, structure and systems to facilitate knowledge management to the organization. There are also a number of ways to design systems to support KM, but few of these deal with the tacit dimension of knowledge and competence. This study focus on a different approach that had not been used for KM researches discussed earlier, that is by having a KM system focusing on competence and proposing a framework as an approach to capture tacit knowledge which focuses on competencies profiling.

\section{REFERENCES}

Adeosun, O.O., T.H. Adeosun and I.A. Adetunde, 2009. Strategic application of information and communication technology for effective service delivery in banking industry. J. Soc. Sci., 5: 47-51. DOI: 10.3844 /jssp.2009.47.51

Al-Anzi, F.S. and K. Al-Zamel, 2005. Efficient maintenance scheduler for near optimum utilization of oil tanks. Am. J. Environ. Sci., 1: 254-253. DOI: 10.3844/ajessp.2005.254.258

Al-Zhrani, S., 2010. Management information systems role in decision-making during crises: case study. J. Comput. Sci., 6: 1247-1251. DOI: 10.3844/jcssp.2010.1247.1251

Anand, G., P.T. Ward and M.V. Tatikonda, 2010. Role of explicit and tacit knowledge in Six Sigma projects: An empirical examination of differential project success. J. Operat. Manage., 28: 303-315. DOI:10.1016/j.jom.2009.10.003

Asprey, L., 2004. Information strategies: are we aligning the business case with enterprise planning. Records Manage. J., 14: 7-13. DOI: $10.1108 / 09565690410528893$
Basu, S. and S.K. Datta, 2010. The success story of voluntary retirement scheme in national carbon company: A unit of Eveready industries India Ltd. Am. J. Econ. Bus. Admin., 2: 157-159. DOI: 10.3844/ajebasp.2010.157.159

Cheng, P., 2010. The application of ionic liquids in catholic coupling of acetophenone. Energy Res. J., 1: 111-115. DOI: 10.3844/erjsp.2010.111.115

Douflou, J., K. Hermans, B. Vandermeulen and B.D. Moor, 2004. User profile integration in knowledge management systems. Proceeding of the International Conference on Competitive Manufacturing (COMA'04), Katholieke Universiteit Leuven, Belgium, pp: 1-6. https://perswww.kuleuven.be/ u0043945/mcknow/ papers.html

Elforgani, M.S. and I. Rahmat, 2010. An investigation of factors influencing design team attributes in green buildings. Am. J. Applied Sci., 7: 976-986. DOI: 10.3844/ajassp.2010.976.986

Elmetwaly, H.M.M., 2011. Design and implementation of medical information systems for managing and following up work flaw in hospitals and clinics. J. Comput. Sci., 7: 27-31. DOI: 10.3844/jcssp.2011.27.31

Hafidh, R.R., A.S. Abdulamir, F.A. Bakar, F. Abas and F. Jahanshiri et al., 2009. Antioxidant research in asia in the period from 2000-2008. Am. J. Pharmacol. Toxicol., 4: 56-74. DOI: 10.3844/ajptsp.2009.56.74

Hanekamp, J.C., 2008. Micronutrients, hormesis and the aptitude for the maturation of regulation. Am. J. Pharmacol. Toxicol., 3: 144-151. DOI: 10.3844/ajptsp.2008.144.151

Jabar, M.A., F. Sidi, M.H. Selamat, 2010. Tacit Knowledge Codification. J. Comput. Sci., 6: 1170-1176. DOI: 10.3844 jcssp.2010.1170.1176.

Jabar, M.A., F. Sidi, M.H. Selamat, A.A.A. Ghani and H. Ibrahim, 2009. An investigation into methods and concepts of qualitative research in information system research. Comput. Inform. Sci., 2: 47-54.

Kuppusamy, M., M. Pahlavani and A.S. Saleh, 2008. Fostering ICT development for growth: Measuring the payoffs for australia and the Asean- 5 countries. Am. J. Applied Sci., 5: 1676-1685. DOI: 10.3844/ajassp.2008.1676.1685

Lindgren, R., D. Stenmark and J. Ljungberg, 2003. Rethinking competence systems for knowledgebased organizations. Eur. J. Inform. Syst., 12: 1829. DOI: $10.1057 /$ palgrave.ejis. 3000442

Mark, A., M. Dino, B. Chimay, J. Anumba and P.M. Carillo et al., 2006. Managing knowledge in the context of sustainable construction., http://itcon.org/2006/4 
Marshall, B. and T. Madhusudan, 2004. Element Matching in Concept Maps. Proceedings of the 4th ACM/IEEE-CS Joint Conference on Digital Libraries, July 7-11, ACM Press, Tucson, Arizona, USA., $\quad$ pp: 186-187. DOI: 10.1109/JCDL.2004.1336117

Merali, Y. and J. Davies., 2001. Knowledge capture and utilization in virtual communities. K-CAP '01 Proceedings of the 1st International Conference on KNOWLEDGE CAPTURE, ACM New York, USA., pp: 92-99. DOI: 10.1145/500737.500754

Muna, S. Hatem, Haider, A. Ramadan and Daniel et al., 2005. e-Learning based on context oriented semantic web. J. Comput. Sci., 1: 500-504. DOI: $10.3844 /$ jcssp.2005.500.504

Novak, J.D. and A.J. Canas, 2006. The theory underlying concept maps and how to construct them. Technical Report IHMC CmapTools 200601. Pensacola, FL: Florida Institute for Human and MachineCognition,

http://cmap.ihmc.us/publications/researchpapers/th eorycmaps

Nyame-Asiamah, F., 2009. Exploiting tacit knowledge through knowledge management technologies. Proceedings of Learning Forum London conference, European Institute for E-Learning (EIfEL), City University, London, pp: 22-24. http://bura.brunel.ac.uk/handle/2438/3613
Rao, C.V.G. and P. Niranjan, 2008. An integrated classification scheme for efficient retrieval of components. J. Comput. Sci., 4: 821-825. DOI: 10.3844/jessp.2008.821.825

Sidi, F., M.A. Jabar, M.H. Selamat, A.A.A. Ghani and M.N. Sulaiman, 2009. Framework for interrogative knowledge identification). Comput. Inform. Sci., 2: 109-115.

Sor, R., 2004. Information technology and organizational structure-vindicating theories from the past. Manage. Dec., 42: 316-329. DOI: 10.1108/00251740410513854

Stevens, R.H., J. Millage and S. Clark, 2010. Waves of knowledge management: The flow between explicit and tacit knowledge. Am. J. Econ. Bus. Admin., 2: 129-135. DOI: 10.3844/ajebasp.2010.129.135

Vandaie, R., 2008. The role of organizational knowledge management in successful ERP implementation projects. Knowl. Based Syst., 21: 920-926. DOI: 10.1016/j.knosys.2008.04.001 